\title{
EVALUATION OF FRACTURE TOUGHNESS OF MEDIUM CARBON LOW ALLOY FORGED STEELS
}

\author{
Chandan B R ${ }^{1}$, C M Ramesha ${ }^{2}$, S.K.Rajendra ${ }^{3}$, Sharanraj. $\mathbf{V}^{4}$ \\ ${ }^{1}$ Assistant Professor, Department of Mechanical Engineering, Alpha College of Engineering, Bangalore, \\ chandanbrmech@gmail.com \\ ${ }^{2}$ Associate Professor, Department of Mechanical Engineering, M SRamaiah Institute of Tech, Bangalore, \\ cmramesha@gmail.com \\ ${ }^{3}$ Associate professor, Department of Industrial Engineering and Management, Dr AIT Bangalore. \\ rajendra.drait@gmail.com \\ ${ }^{4}$ Research Scholar, Department of Mechanical Engineering, M.S.R.I.T, Bangalore, \\ sharanraj407@gmail.com
}

\begin{abstract}
The purpose of the work is to determine the critical stress intensity factor K1C, according to ASTM E399 named as plane strain fracture toughness. The specimen used is chevron notchedCompact Tension specimen (CT-specimen) to create a fatigue crack by cycling the sample to minimum and maximum loads. Polyethylene glycol (PEG) $\mathrm{H}-(\mathrm{O}-\mathrm{CH} 2-\mathrm{CH} 2) n-\mathrm{OH}$ as quenchant was studied to investigate the fracture toughness $(K 1 C)$ on the medium carbon low alloy forged steels in heat treated condition by hardening and step tempering process. The step tempering process of the $30 \%$ polymer quenched specimen results high fracture toughness compare to $10 \%$ polymer quenched and as forged samples. By heat treatment the microstructure of the steels is also varied and its effect on the fracture toughness is also observed. It has been found that fine grained structure results high fracture toughness. The microstructural examination of the samples were found to have justified reason for the increment recorded in some of the mechanical properties, as it displayed a high proportion of the martensitic phase.
\end{abstract}

Keywords:Fracture toughness (K1C), Polyethylene glycol (PEG), Microstructure.

\section{INTRODUCTION}

Medium carbon low alloy steel is being used in the forged condition in the automobiles, aerospace and transportation industries. Reliability of critical components made of EN Series is directly based on the toughness of the steel, which in turn is dependent on forging conditions. A review of literature shows that substantial information is available relating to fracture toughness of medium carbon low alloys forged steels [1]. EN Series 18 (AISI 5140), 19 (AISI 4140), 24 (AISI 4340) and 25 (3430) are medium carbon low alloy steels under HSLA categories.Hardening heat treatment develops extreme hardness but reduces toughness, hence they become brittle and are unsuitable to be used in most service conditions, and hence step tempering is carried out to increase the toughness. The synthetic quenching medium as PEG[2], are used for the quenching of the heat treated parts. The uses of synthetic quenchant have advantages compare to convention type of quenchants, due to less risk of cracking and less distortion. Fracture toughness is a property which describes the ability of a material containing a crack to resist fracture.The (CT-specimen)[3],samples were characterized using servo-hydraulic test machines, which cover a range of load capacities up to $100 \mathrm{KN}$.In practice, heat treatment is the process by which change in fracture toughness can be achieved. It is mainly depends on the microstructural transformation, he microstructural changes occur at different heat treatment condition with varying the holding time and with varying the tempering

temperature. The heat treatment of steels gives improved in fracture toughness. The synthetic quenching medium as PEG are used for the

quenching of the heat treated parts. The effect of polyethylene glycol as quenchant studied with a view to investigate the fracture toughnessand microstructural evaluation of steels. The microstructure ofquenching and tempering parts produces the fine tempered martensitic structure which yields the high strength.

\section{MATERIALS AND METHOD}

The chemical composition of medium carbon low alloy steels used for the examination is given in Table 1.

\subsection{Heat Treatment/ Quenching and Step Tempering}

The prepared forged samples were taken for the heat treatment process. The furnace used is electrical furnace, where the maximum heating temperature is $1200^{\circ} \mathrm{C}$.The samples were heated at a certain predefined temperature and held at that temperature for a period of $60 \mathrm{~min}$. where the 
homogeneous phase transformation takes place. Then the heated samples were directly quenched in the quenching medium which is already prepared for the hardening process. The samples were directly quenched in the polymer solution which constitutes the water and polymer at different proportion. Quenchant used in the hardening process is polymer solution. The preparation of the solution is done before carrying the hardening process. The proportion of the mixture used is $10 \%$ and $30 \%$ polymer the ratio is $1: 9$ and 3:7.Then directly

the heated samples were quenched in the quenching medium which is already prepared for the hardening process the heated samples

were quenched in the quenching medium which is already prepared for the hardening process.

After hardening process the step tempering is carried out further.Table 2.Shows the temperature and soaking time of the steels.

Table 2.Temperature and soaking time [5]

\begin{tabular}{|l|l|l|}
\hline Process & Temp $^{\mathbf{}} \mathbf{C}$ & Soaking time \\
\hline Hardening & 855 & 60 Min \\
\hline
\end{tabular}

\begin{tabular}{|l|l|l|}
\hline Tempering I & 575 & 60 Min \\
\hline Tempering II & 220 & 60 Min \\
\hline
\end{tabular}

The material is heated in the heat treatment furnace for the maximum hardeningtemperature at $855^{\circ} \mathrm{C}$ and soaking period for about $60 \mathrm{~min}$. The samples were quenched in the prepared solution. Step tempering is done on the hardened samples at $575{ }^{\circ} \mathrm{C}$ for about $60 \mathrm{~min}$ and then the samples werecooled in the air, again tempered at $220^{\circ} \mathrm{C}$ for $60 \mathrm{~min}$.

\subsection{Test Specimen Preparation [3]}

A set of samples was prepared for the fracture toughness test and for microstructural analyses. The standards used for the samples to carry out the test are ASTM E399, Standard compact specimentoughness is a chevron notched and fatigue cracked plate loaded in tension. The general proportions of this specimen configuration are shown in fig 1.

\subsection{Method for determining fracture toughness}

ASTM E399 standard test method is used to findthe plain strain fracture toughness of metallic materials. The Loading method preferred for the examination is tensile load.

Table 1. Chemical composition [4]

\begin{tabular}{|c|c|c|c|c|c|c|c|c|c|}
\hline \multirow{2}{*}{ Steel } & \multirow{2}{*}{ Element } & \multicolumn{8}{|c|}{ Wt \% } \\
\hline & & C & Mn & $\mathbf{P}$ & $\mathbf{S}$ & $\mathbf{S i}$ & $\mathbf{N i}$ & $\mathrm{Cr}$ & Mo \\
\hline \multirow{2}{*}{$\begin{array}{l}\text { EN18 } \\
\text { (AISI 5140) }\end{array}$} & Min & 0.35 & 0.65 & 0 & 0 & 0.10 & -- & 0.85 & -- \\
\hline & Max & 0.45 & 0.95 & 0.040 & 0.040 & 0.35 & -- & 1.15 & -- \\
\hline \multirow{2}{*}{$\begin{array}{l}\text { EN19 } \\
\text { (AISI4140) }\end{array}$} & Min & 0.38 & 0.75 & 0 & 0 & 0.15 & -- & 0.80 & 0.15 \\
\hline & Max & 0.43 & 1.10 & 0.035 & 0.040 & 0.30 & -- & 1.10 & 0.25 \\
\hline \multirow{2}{*}{$\begin{array}{l}\text { EN24 } \\
\text { (AISI4340) }\end{array}$} & Min & 0.37 & 0.60 & 0 & 0 & 0.15 & 1.65 & 0.70 & 0.20 \\
\hline & Max & 0.43 & 8.80 & 0.035 & 0.040 & 0.30 & 2.00 & 0.90 & 0.30 \\
\hline \multirow{2}{*}{$\begin{array}{l}\text { EN25 } \\
\text { (AISI3430+Mo) }\end{array}$} & Min & 0.27 & 0.45 & 0 & 0 & 0.10 & 2.30 & 0.50 & 0.45 \\
\hline & Max & 0.35 & 0.70 & 0.04 & 0.04 & 0.40 & 2.80 & 0.80 & 0.65 \\
\hline
\end{tabular}

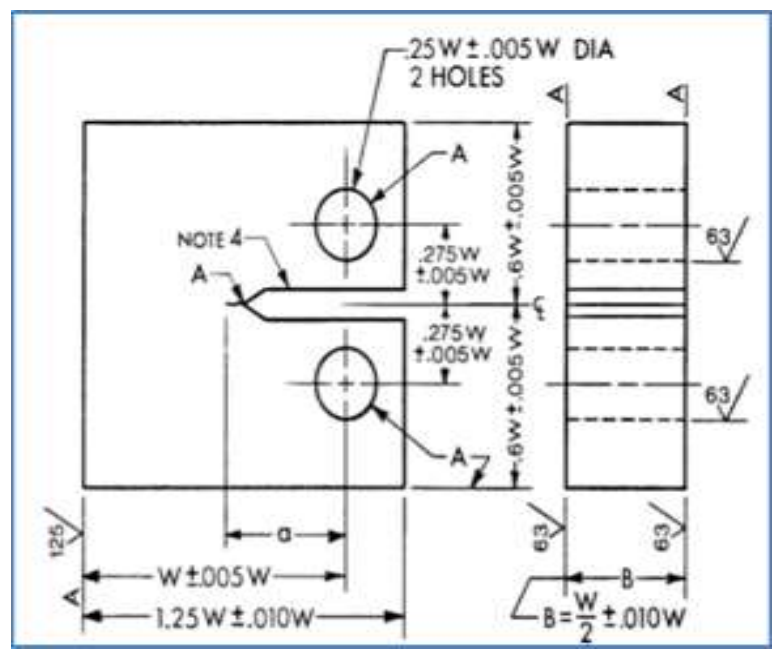

Fig 1. CT-specimen Standard proportions and tolerances
$\mathrm{K}_{\mathrm{IC}}=$ Plane strain fracture toughness

$\mathrm{B}=$ specimen thickness $\mathrm{a}=$ nominal crack growth $\mathrm{W}=$ width of the specimen $\mathrm{K}=$ stress intensity factor $\mathrm{a} / \mathrm{w}=$ should be around 0.5

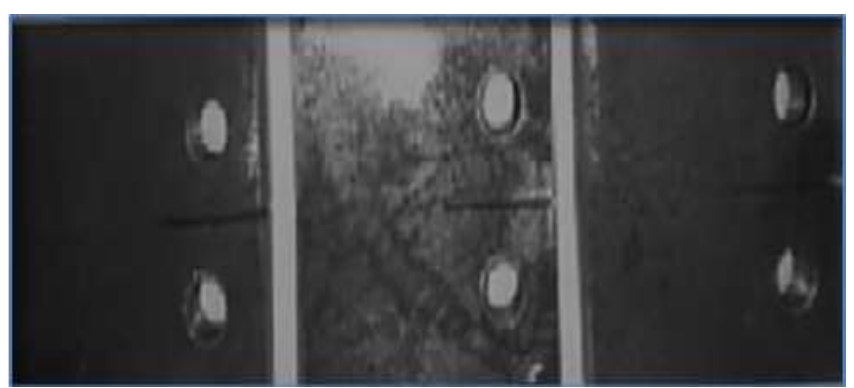

Fig 2.Samplesfor Fracture Toughness $\left(\mathrm{K}_{1 \mathrm{C}}\right)$ test 


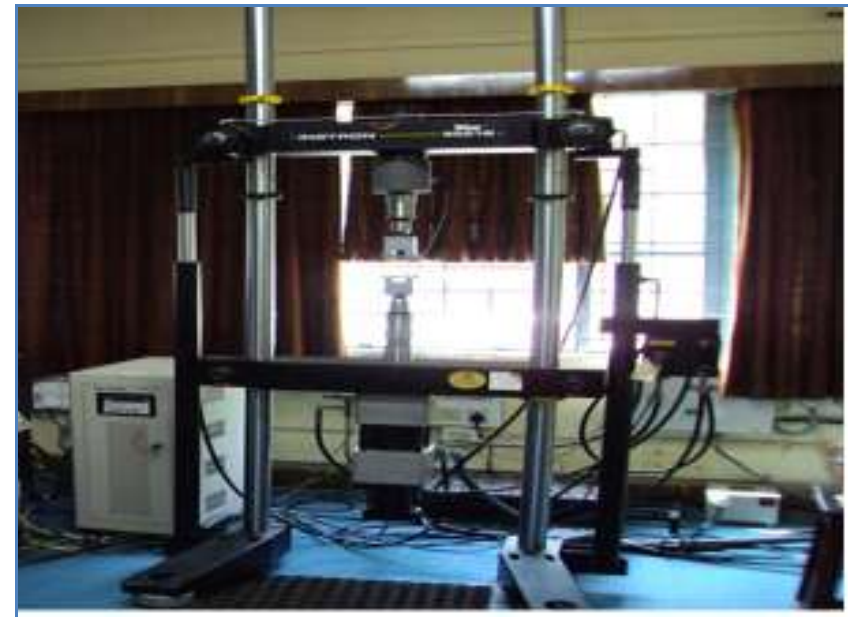

Fig 3.Servo-Hydraulic Test Machine

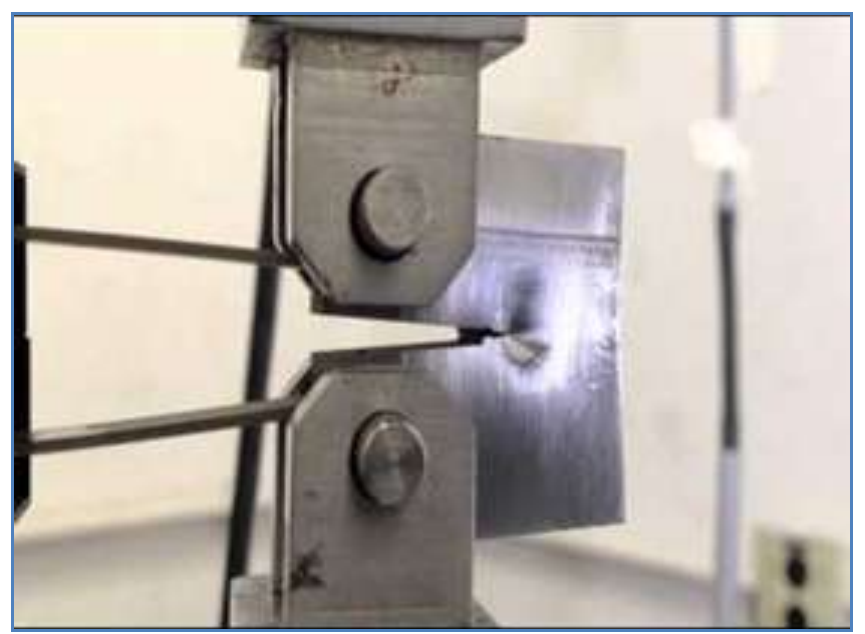

Fig 4. Tensile loading for $\mathrm{K}_{\mathrm{IC}}$ test
2.4 Determination of $\mathbf{K}_{\mathrm{IC}}$ : Critical stress intensity factor is also named as plain strain fracture toughness [6], due to toughness of the material, chevronnotched (CT-specimen) must be used in order to get the valid test according to ASTM E399.

$\mathrm{K}=\mathrm{K}_{\mathrm{IC}}($ Crack is critical $)=\mathrm{Y} \sigma \sqrt{\pi \alpha}$

$\sigma=$ Nominal stress

$\mathrm{Y}=$ Geometry correction factor depends on crack shape and size, specimen shape and size,

$\mathrm{Y}=\{\operatorname{Cos}(\pi \mathrm{a} / \mathrm{w})\}^{1 / 2}$

$\mathrm{P}_{\text {Max }}=$ Maximum Applied force

$\mathrm{A}=$ Area

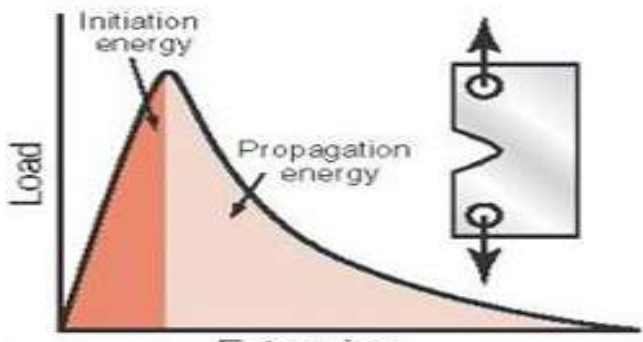

Extension

2.5 Determination of $\mathbf{J}_{\mathrm{IC}}: \mathrm{J}_{\mathrm{IC}}$ can be used for quality control and allows the determination of a theoretical $\mathrm{J}_{\mathrm{IC}}$ [7], value through the equation (2), applying equation (1) values.

$\mathrm{J}_{\mathrm{IC}}=\left(1-\boldsymbol{v}^{2} / \mathrm{E}\right) * \mathrm{~K}^{2}$

Where $\boldsymbol{v}(0.30)$ is Poisson's ratio

$\mathrm{E}=$ Young's modulus

$\mathrm{K}=\mathrm{K}_{\mathrm{IC}}$,Plain strain fracture toughness

\section{RESULTS AND DISCUSSIONS}

Table 3. Shows the Mechanical properties of forged and polymer quenched steel samples

\begin{tabular}{|c|c|c|c|c|c|c|c|}
\hline $\begin{array}{l}\text { EN } \\
\text { Series }\end{array}$ & $\begin{array}{l}\text { Sample } \\
\text { quenching } \\
\text { medium }\end{array}$ & $\begin{array}{l}\text { Tempering } \\
\text { Temperature }\left({ }^{\circ} \mathrm{C}\right)\end{array}$ & $\begin{array}{l}\text { Force } \\
(\mathrm{N})\end{array}$ & $\begin{array}{l}\text { Nominal } \\
\text { stress } \\
\text { N/mm }\end{array}$ & $\begin{array}{l}\text { Tensile } \\
\text { strength } \\
\mathrm{N} / \mathrm{mm}^{2}\end{array}$ & $\begin{array}{l}\mathrm{K}_{\mathrm{IC}} \\
\mathrm{Mpa} \sqrt{m}\end{array}$ & $\begin{array}{l}\mathbf{J}_{\mathbf{I C}} \\
\mathbf{K J} / \mathbf{M}^{2}\end{array}$ \\
\hline \multirow{3}{*}{ EN 18} & As Forged & ---------- & 5795.9 & 6.182 & 819.7 & 34.8 & 35.6 \\
\hline & $10 \%$ Polymer & 575,220 & 6737.4 & 7.18 & 952.8 & 42.6 & 69.09 \\
\hline & $30 \%$ Polymer & 575,220 & 7267.0 & 7.75 & 1027.7 & 46.1 & 75.02 \\
\hline \multirow{3}{*}{ EN 19} & Forged & ---------- & 5913.6 & 6.30 & 836.3 & 37.4 & 40.4 \\
\hline & $10 \%$ Polymer & 575,220 & 6923.4 & 7.384 & 1135.9 & 43.8 & 71.15 \\
\hline & $30 \%$ Polymer & 575,220 & 7393.4 & 7.886 & 1098.9 & 46.8 & 75.98 \\
\hline \multirow{3}{*}{ EN 24} & Forged & ----------- & 6423.5 & 6.851 & 894.3 & 40.6 & 43.78 \\
\hline & $10 \%$ Polymer & 575,220 & 7649.5 & 8.159 & 1081.8 & 48.4 & 78.59 \\
\hline & $30 \%$ Polymer & 575,220 & 7816.2 & 8.337 & 1105.4 & 49.5 & 80.29 \\
\hline \multirow{3}{*}{ EN 25} & Forged & ------------ & 6777.3 & 7.229 & 923.3 & 42.9 & 46.42 \\
\hline & $10 \%$ Polymer & 575,220 & 8123.5 & 8.665 & 1212.2 & 51.4 & 83.46 \\
\hline & $30 \%$ Polymer & 575,220 & 8354.7 & 8.911 & 1239.9 & 52.9 & 85.74 \\
\hline
\end{tabular}




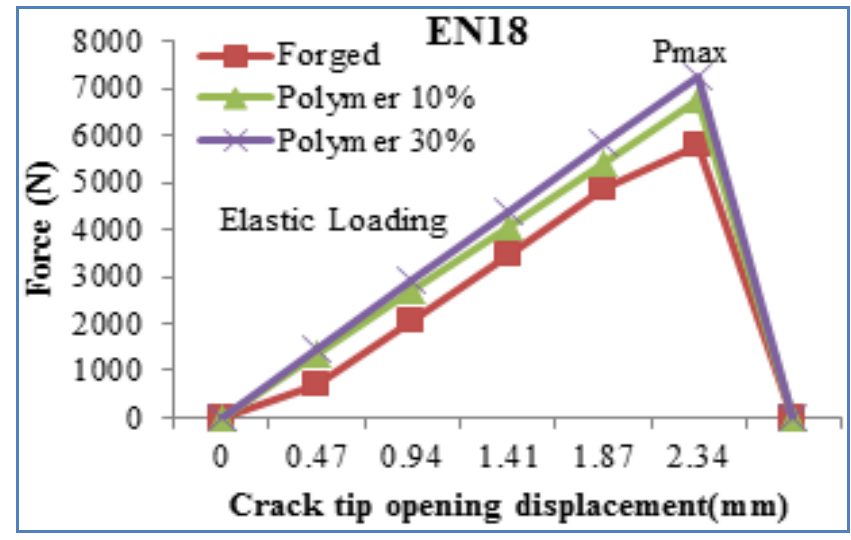

Fig 5. Principal Types of EN18 Force-Displacement Records

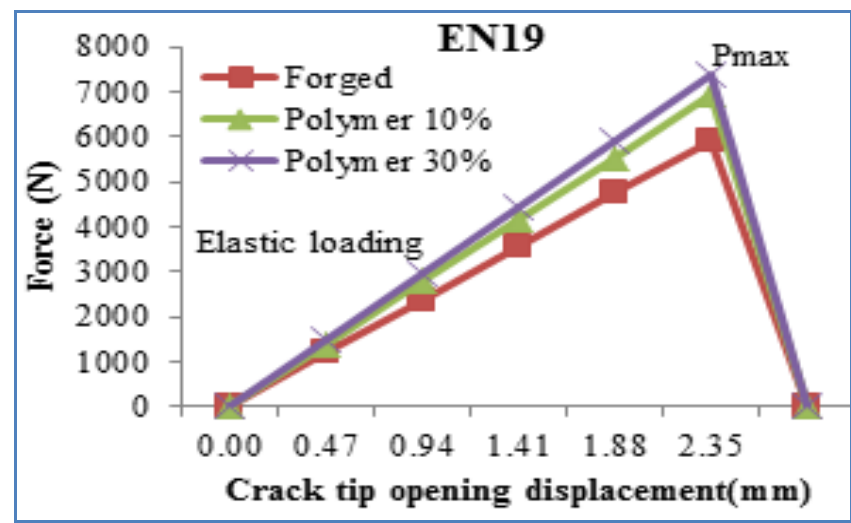

Fig 6. Principal Types of EN19 Force-Displacement Records

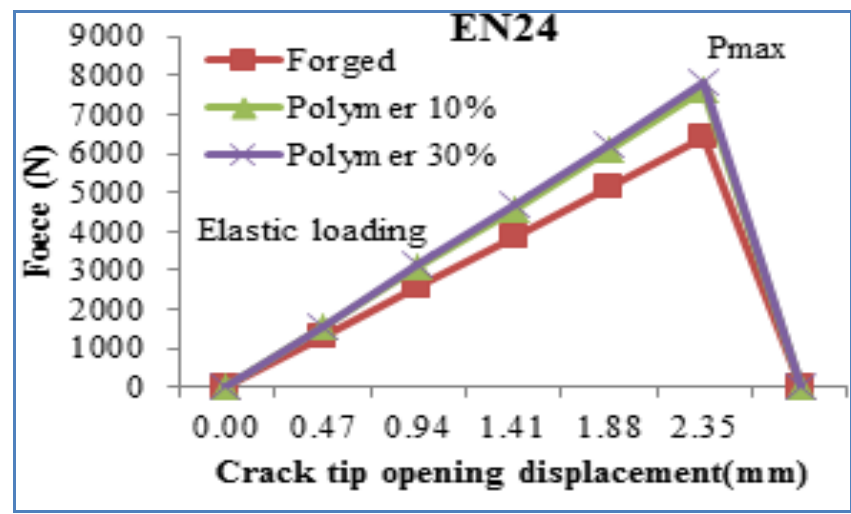

Fig 7. Principal Types of EN24 Force-Displacement

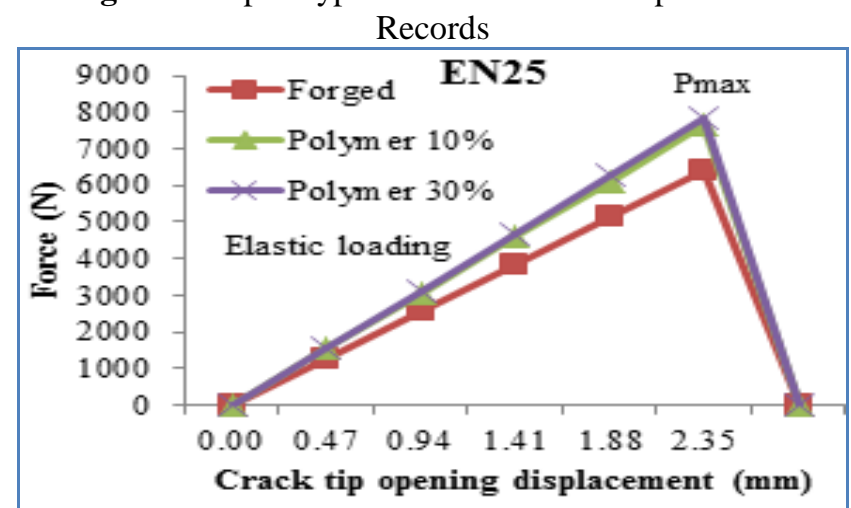

Fig 8. Principal Types of EN25 Force-Displacement Records
Observation: The maximum load value recorded by the machine, $\mathrm{P}_{\max }$ is for $30 \%$ polymer quenched EN 18, $19,24 \& 25$ steels compare to $10 \%$ polymer quenched and as forged samples.

\section{METALOGRAPHY}

The microstructural investigation[8], was performed using a Carl Zeiss optical microscope. In sequence, the steps include sectioning, mounting, course grinding, fine grinding, polishing, etching and microscopic examination. Thesamples were polished using a series of emery papers of grit size varying from $1000 \mu \mathrm{m}-1500 \mu \mathrm{m}$.High napped polishing pads with a colloidal alumina polishing abrasive is used.The polishing times should nominally be less than 30 seconds. The samples were etched with Nital solution, 100 $\mathrm{ml}$ Ethanol and 1-10 ml Nitric acid for about $10-20$ seconds before observation in the optical microscope.

Observation:Medium carbon low alloy forged steel vs. polymer quenched and tempered steels have strong influence on fracture toughness $\left(\mathrm{K}_{\mathrm{IC}}\right)$. The polymer quenched and tempered steels results high fracture toughness value for as forged samples. The microstructure of forged sample consists of proeutectoid ferrite and pearlite. The white region results the proeutectoid ferrite and black region results pearlite in the microstructure. The resultant pearlite is resolved into alternative phases of ferrite and cementite. The microstructure of polymer quenched and tempered steel consists of fine tempered martensite with the small amount of ferrite.By step tempering retained austenite converts into non equilibrium but more stable phases like troosite, sorbite or bainite, which improve ductility, toughness and impact strength.

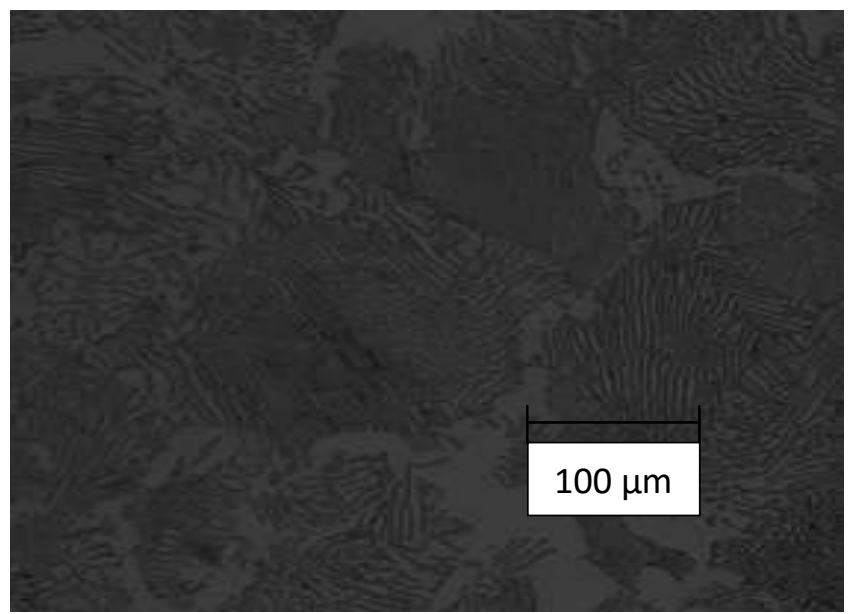

Fig 9: Microstructure of EN18 steel in Forged condition 


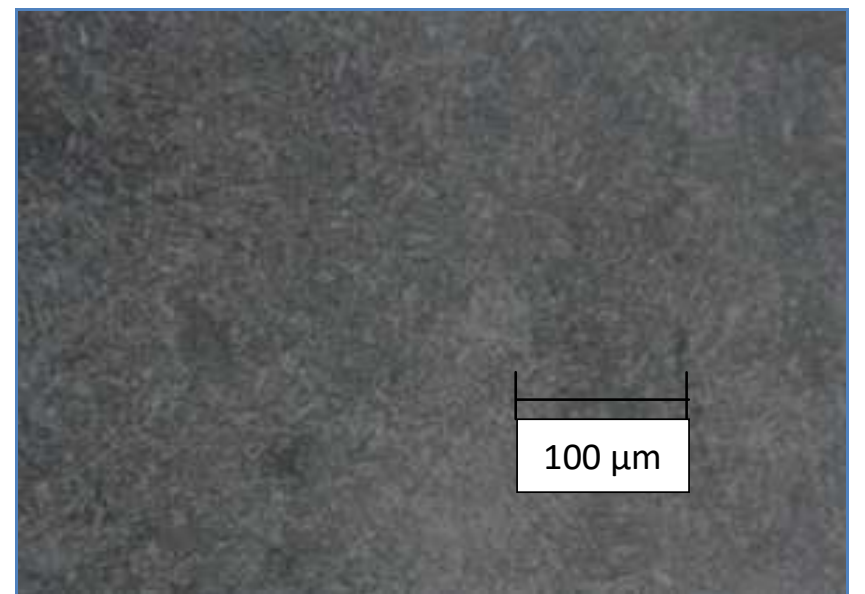

Fig 10: Microstructure of EN18 steel quenched in 10\% Polymer solution.

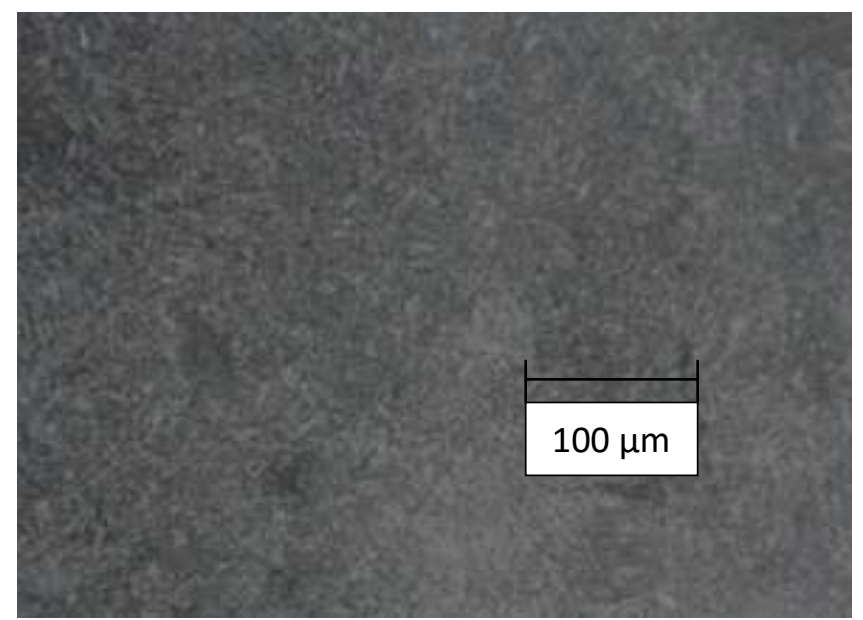

Fig 11: Microstructure of EN18 steel quenched in 30\% Polymer solution.

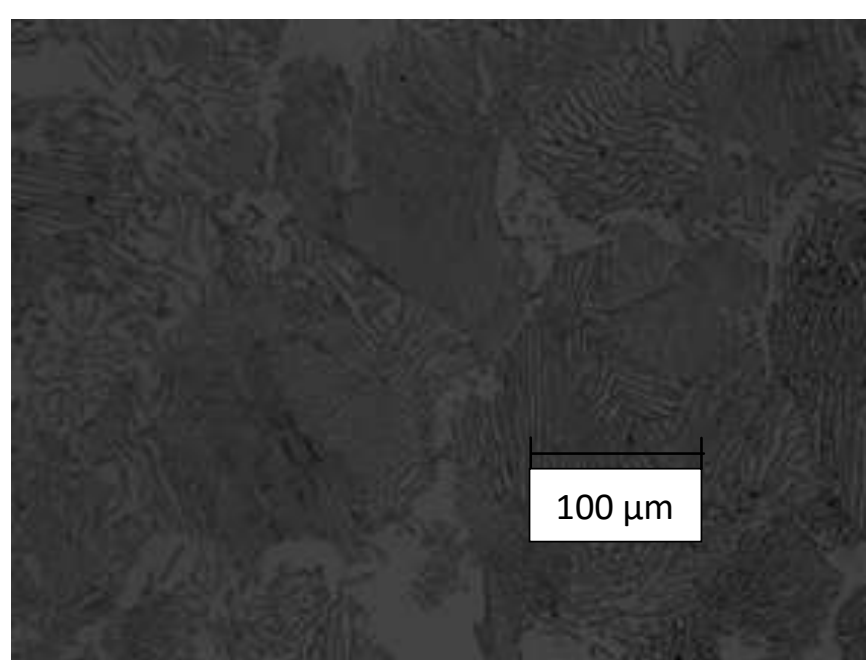

Fig 12: Microstructure of EN19 steel in Forged condition

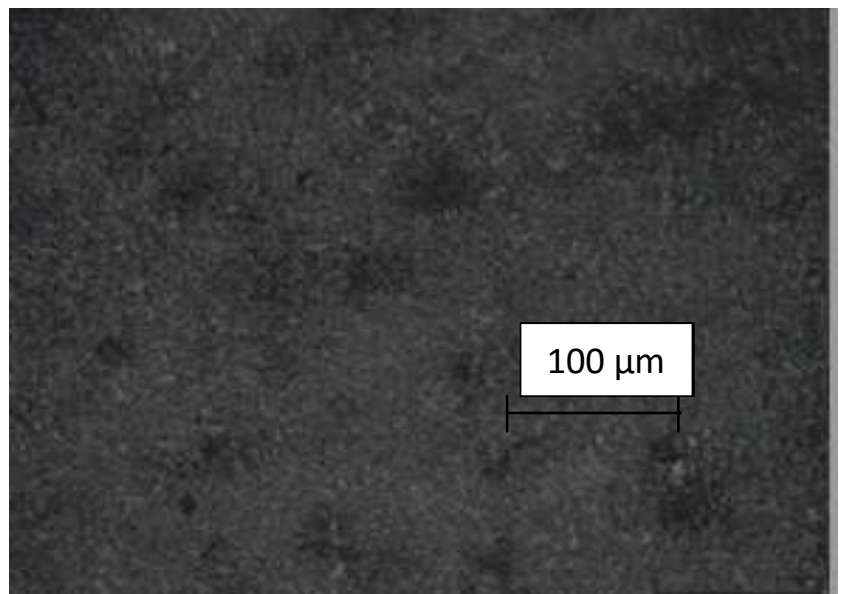

Fig 13: Microstructure of EN19 steel quenched in 10\% Polymer solution.

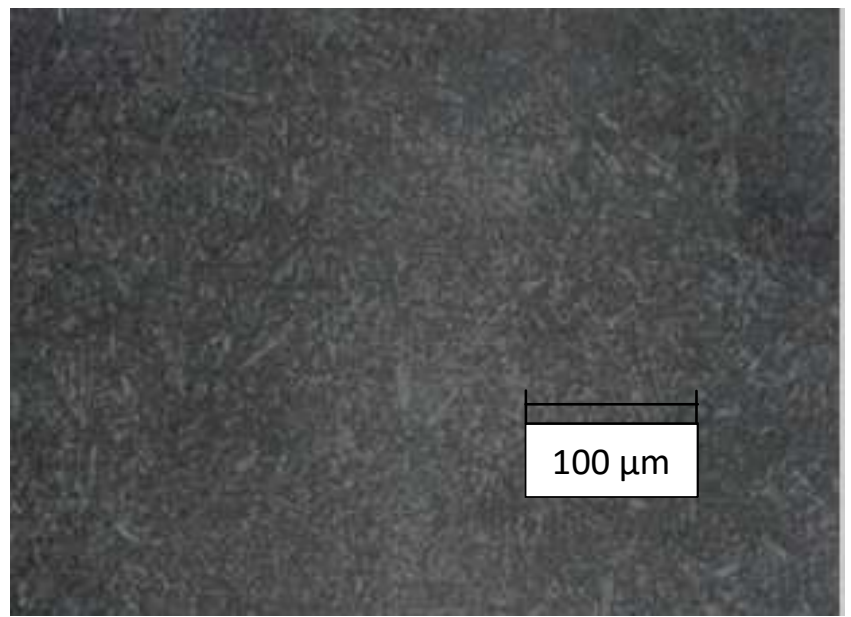

Fig 14: Microstructure of EN19 steel quenched in 30\% Polymer solution.

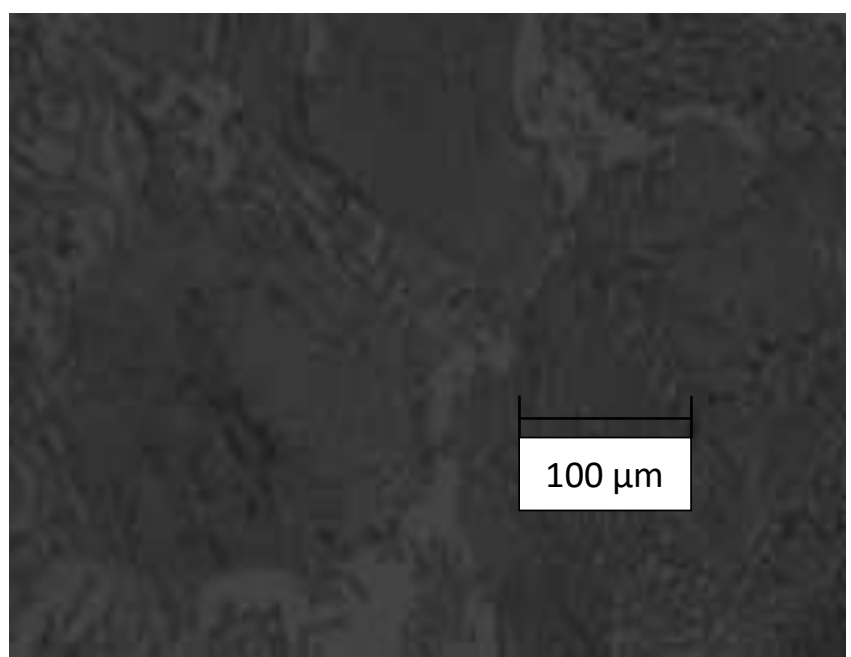

Fig 15: Microstructure of EN24 steel in Forged condition 


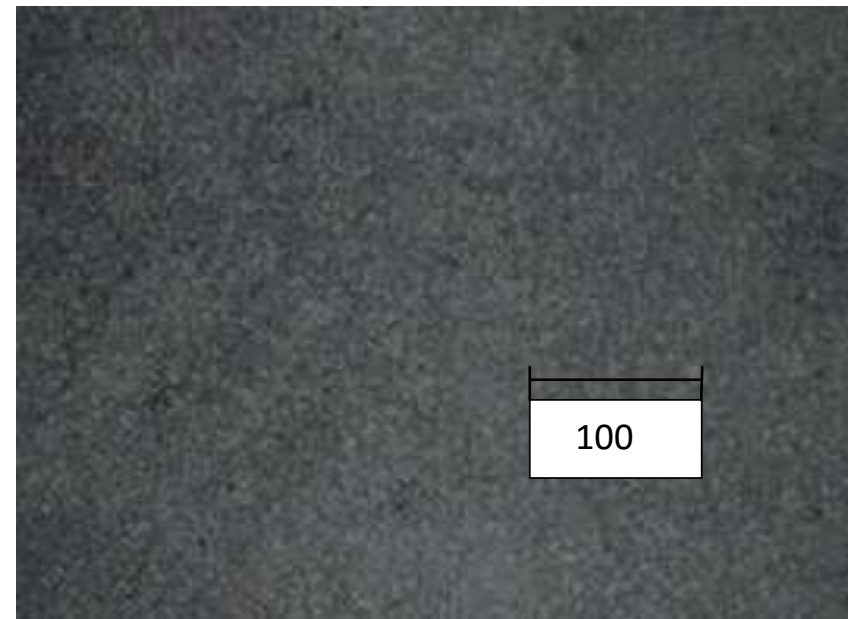

Fig 16: Microstructure of EN24 steel quenched in 10\% Polymer solution

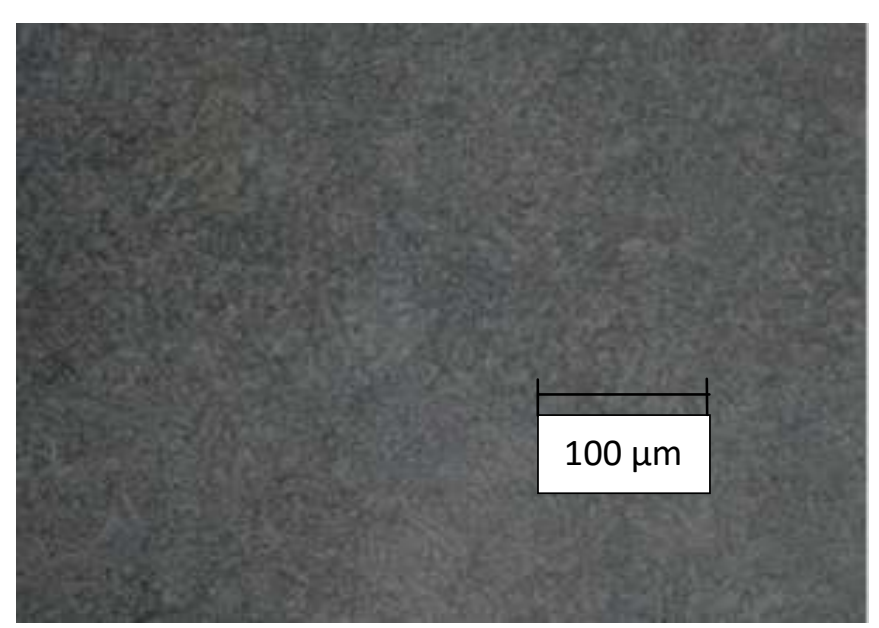

Fig 17: Microstructure of EN24 steel quenched in 30\% Polymer solution.

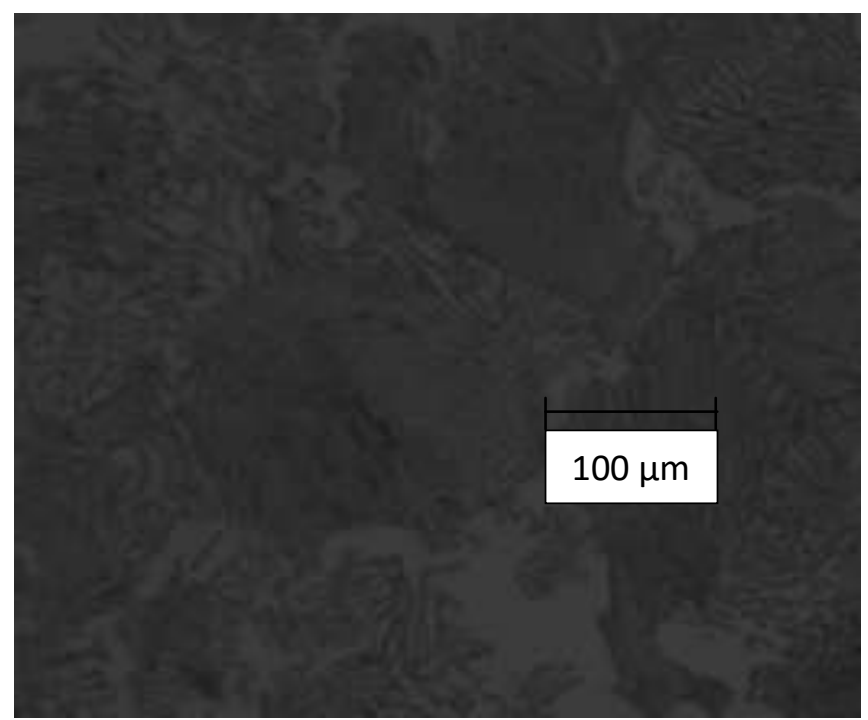

Fig 18: Microstructure of EN25 steel in Forged condition

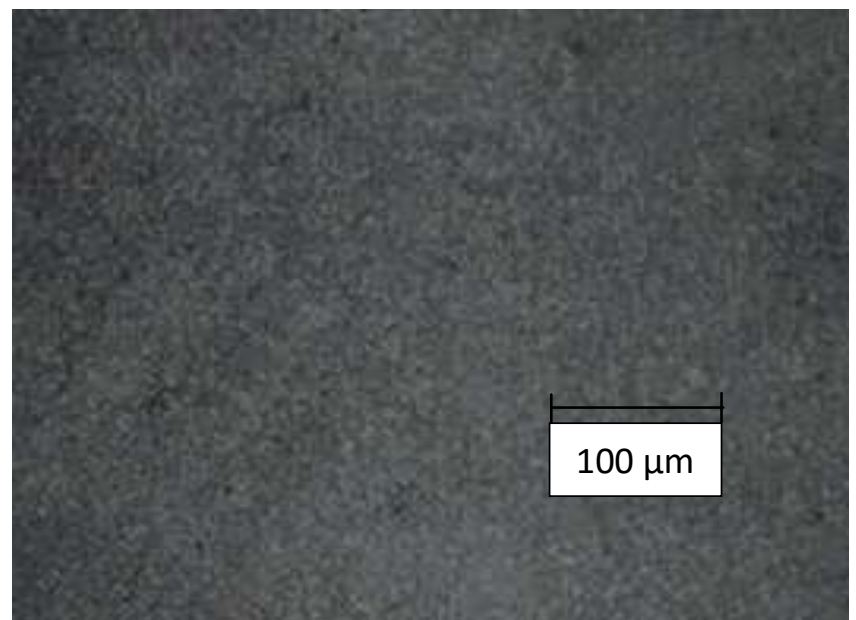

Fig 19: Microstructure of EN25 steelquenched in $10 \%$ Polymer solution

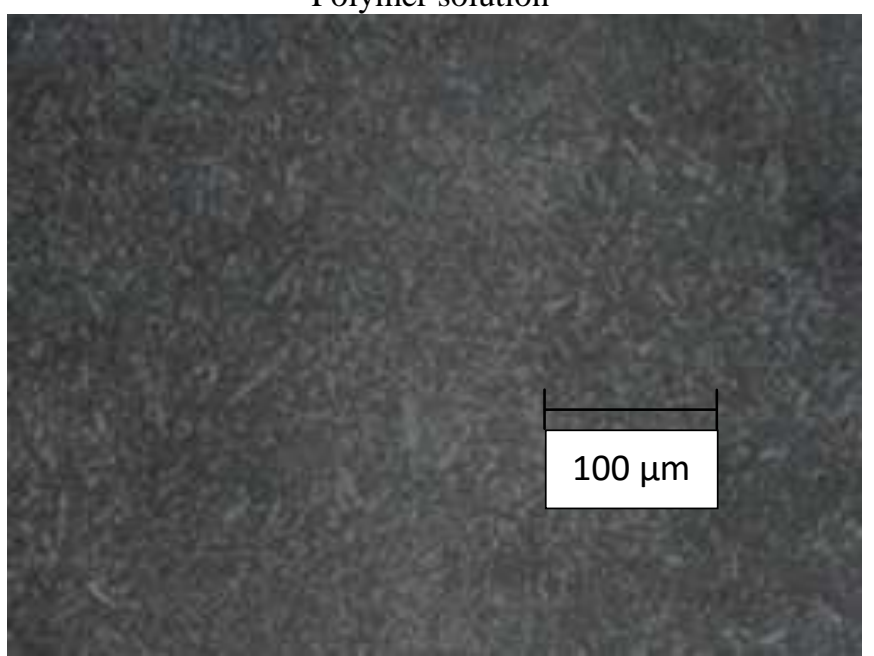

Fig 20: Microstructure of EN25steel quenched in 30\% Polymer solution.

\section{FRACTOGRAPHY [9]}

The fatigue fractured specimen surfaces was examined using a Scanning Electron Microscope (LEICA 4401) with the Secondary electron imaging performed using an applied voltage of $20 \mathrm{KV}$.

Observation:A fine grained structure results better resistance to crack propagation results in higher fracture toughness due to higher grain boundary.

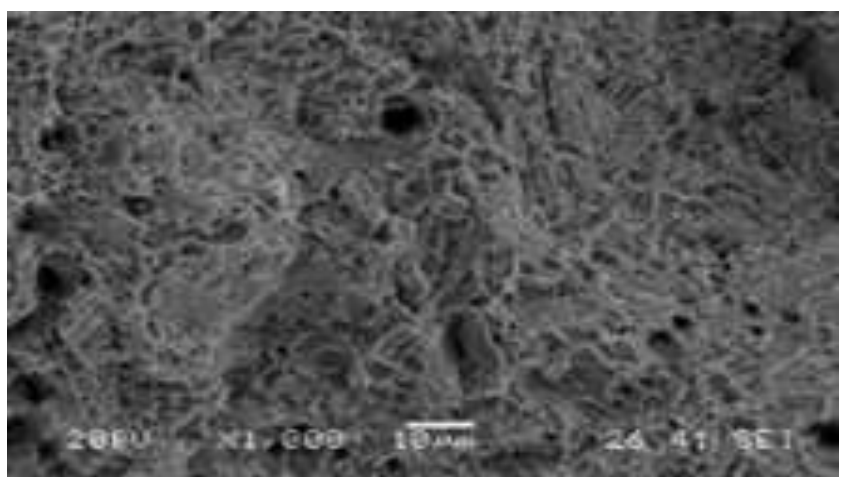

Fig 21: Fractured surfaces of EN18 steel quenched in 30\% Polymer solution 


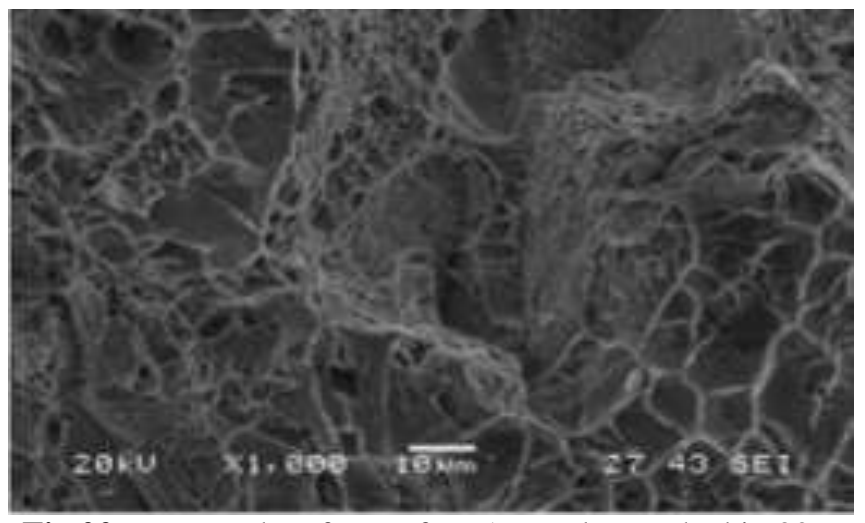

Fig 22: Fractured surfaces of EN19 steel quenched in $30 \%$ Polymer solution

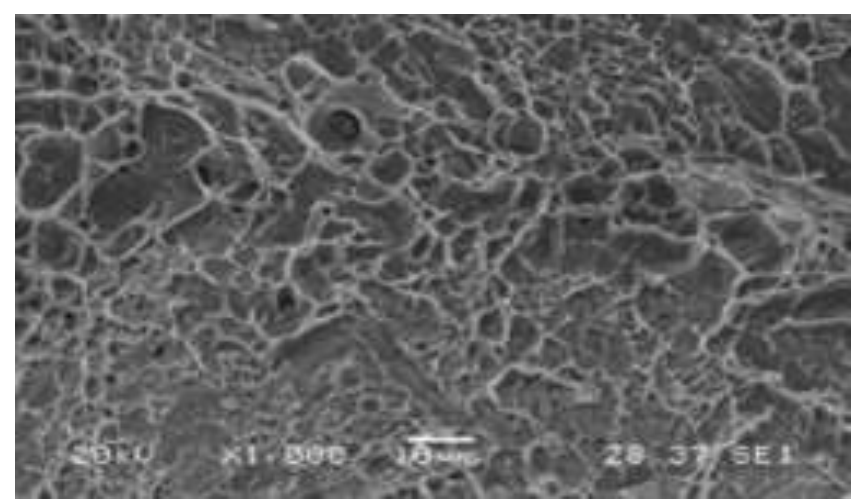

Fig 23: Fractured surfaces of EN24 steel quenched in 30\% Polymer solution

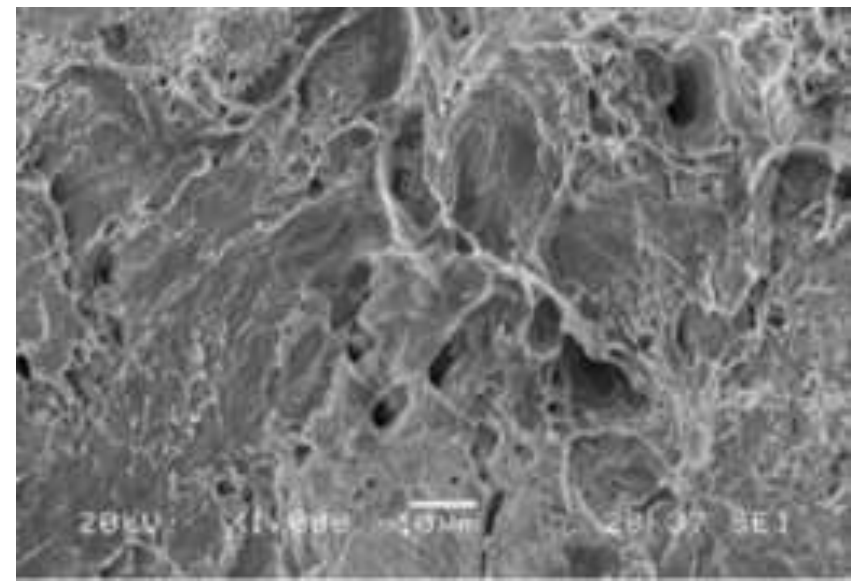

Fig 24: Fractured surfaces of EN25 steel quenched in 30\% Polymer solution

\section{CONCLUSION}

This study tends to investigate the Fracture Toughness of Medium Carbon Low Alloy Forged steels vs. Polymer Quenched steels

[1]. The following conclusions were made from the results obtained:

[2]. The step tempering process of the samplesresults high fracture toughness.

[3]. PEG is preferred as a quenching medium to minimize the stresses and cracking due to uniform cooling rate then the water, ice and brine solution.
[4]. The ultimate tensile strength increases with increase in polymer concentration.

[5]. The fracture toughness of $30 \%$ polymer quenched samples results high compare to $10 \%$ polymer quenched and forged samples for the same notch depth and thickness.

[6]. The microstructure of polymer quenched and tempered steel consists of fine tempered martensite with the small amount of ferrite.

[7]. A fine grained structure has been found to have higher value of $\mathrm{K}_{1 \mathrm{C}}$ than a coarse grained structure.

The fracture surface of the polymer quenched samples follows the grains of the material, where cracks that takes place along the grain boundary.

\section{ACKNOWLEDGEMENT}

The authors express heartfelt thanks to Management of Gokula Education Foundation (GEF) and Department of Mechanical Engineering, MSRIT Bangalore-560054 provided all facility to carry out this research work.

\section{REFERENCES}

[1]. "Classification and Designation of Carbon and Low Alloy Steel”; ASM Handbook Volume 1(1990 edition) pg-354-394.

[2]. M. Momoh, B. J. Bamike, A. M. Saliu, O. A. Adeyemi "Effects of Polyethylene Glycol on the Mechanical Properties of Medium Carbon Low Alloy Steel" Nigerian Journal of Technological Development, vol. 12, no.2, December 2015.

[3]. Standard Test Method for Plane-Strain Fracture Toughness of Metallic Materials1

[4]. American society for testing and materials 100 Barr Harbor Dr. west Conshohocken, PA 19428 reprinted from the Annual Book of ASTM Standards. Copy right ASTM.

[5]. PhilipT.V. Thomas J. and Caffery. "Properties and selection - Iron, Steels and high Performance Alloys", ASM Hand Book Vol-1, ASM International, Ohio (1961) 1119 - 1127.

[6]. Becherer B.A. and Witheford T.J., "Heat Treating of Ultra-high-strength Steels, ASM Hand Book Vol-4, ASM International, Ohio (1961) 495.

[7]. [6]Bahram Farahmand,"Virtual Testing and Predictive Modeling": For Fatigue and Fracture Mechanics Allowables,Springer Science \& Business Media, 29-Jun-2009,Pg 70-80.

[8]. KL Murthy, M450, Griffith Theory (Fracture)http://www4.ncsu.edu/ murty/MAT450/N OTES/fracture2.pdf.

[9]. Donald C. Zipperian, Ph.D. Pace Technologies, Metallographic Specimen Preparationbasic,www.metallographic.com

[10]. Shi, X., Wang, W., Ye, W., Sha, W., Shan, Y., Shen, M., \& Yang, K. "Light and electron microscopy of microstructure and fractography of an ultrahighstrength martensitic steel" 28(1), 7-10, 2014.

[11]. S. K. Nath* and Uttam Kr Das** "Effect of Microstructure and notches on the Fracture 
Toughness of Medium Carbon

Steel'http://jname.8m.net, June, 2006.

[12]. S. K. Maity ${ }^{1}$ and R. Kawalla "Ultrahigh Strength Steel: Development of Mechanical Properties through Controlled Cooling" NationalMetallurgicalLaboratory, $\quad{ }^{2} \mathrm{TU}$ Bergademie, ${ }^{1}$ India ${ }^{2}$ Germany.

[13]. Ismar Hajro ,Damir Hodzi "The relationship between quasi-static and Impact Toughness" 14th International Research/Expert Conference "Trends in the Development of Machinery and Associated Technology" TMT 2010, Mediterranean Cruise, 1118 September 2010.

[14]. Standards Measurement \& Testing Project No. SMT4-CT97-2165, Manual of Codes of Practice for the Determination of Uncertainties in Mechanical Tests on Metallic Materials, UNCERT COP 03: 2000.

[15]. T.J. Grant ${ }^{\text {a, }}$ L. Weber ${ }^{\text {b, }}$, A. Mortensen ${ }^{\text {b,1 }}$ "Plasticity in Chevron-notch fracture toughness testing"Engineering Fracture Mechanics 67 (2000) 263-276.

[16]. K.K.Alanemea,b*,S. Ranganathana, T. Mojisolab, "Mechanical Behaviour of Duplex Phase Structures in a Medium Carbon Low Alloy Steel"jmmce.org,Vol. 9, No.7, pp.621-633, 2010.

[17]. M.S. Sham Prasad ${ }^{* 1}$, C.S. Venkatesha ${ }^{2}$, T.Jayaraju ${ }^{3}$ "Experimental Methods of Determining Fracture Toughness of Fiber Reinforced Polymer Composites under Various Loading Conditions" jmmce.org, Vol. 10, No.13, pp.1263-1275, 2011.

[18]. José R. Tarpani*, Maria H.P. Braz, Waldek W. Bose Filho and DirceuSpinelli, Microstructural and Fractographic Characterization of a Thermally Embrittled Nuclear Grade Steel: Part II - Quenching and Tempering"Vol. 5, No. 3, 2002.

[19]. C. M. Ramesha, Ph.D. thesis on "A study on suitability criteria of steels with lower alloy contents for semi critical application maintaining reliability and structural integrity by process modifications" 2003-2010.

[20]. Torsten Ericsson, "Principleof Heat treating of Steels"; ASM Handbook Volume 4(1991 edition) pg$14-25$.

[21]. ASM Handbook "Heat Treating" - Volume 4.

[22]. Kenneth Kanayo Alaneme, "Fracture Toughness (K1C) evaluation for dual phase medium carbon low alloy steels using circumferential notched tensile (CNT) samples"Mat. Res. vol.14 no.2 São Carlos 2011 Epub May 20, 2011.

[23]. https://en.wikipedia.org/wiki/Fracture_toughness. 